\title{
Análise dos processos cognitivos e autopoiéticos em um ambiente virtual de aprendizagem
}

\section{Analysis of the cognitive and autopoietic processes in a virtual learning environment}

\author{
Carla Beatris Valentini* \\ Claudia Alquati Bisol ${ }^{* *}$
}

\begin{abstract}
RESUMO
O suporte multimídia em ambientes de aprendizagem pode ser um elemento facilitador para mudanças de concepções epistemológicas por parte de educadores e aprendizes. Este artigo constitui-se em um estudo de caso. O corpus de análise é composto pelos enunciados de um aprendiz que interagiu no ambiente virtual de aprendizagem de uma disciplina obrigatória de um curso de graduação em Psicologia. A teoria da Equilibração de Piaget e a Biologia do Conhecimento de Maturana são as teorias que sustentam a análise e que dão suporte à construção dos indicadores cognitivos e autopoiéticos. A análise evidencia como o sujeito interage diante de trocas realizadas nos diferentes cenários do ambiente virtual. Os indicadores autopoiéticos e cognitivos evidenciam um processo de aprendizagem sustentado pela interação com o outro e pela interação com o próprio objeto de conhecimento. As contribuições do sujeito indicam um movimento de autoria e de construção de conhecimento, assumindo um papel participativo e responsável nas trocas efetuadas com os demais aprendizes.
\end{abstract}

Palavras-chave: ambientes virtuais de aprendizagem; interação; processos cognitivos; autopoiese; educação a distância.

* Doutora em Informática na Educação PGIE/UFRGS, Mestre em Psicologia pela UFRS, Universidade de Caxias do Sul. E-mail: cbvalent@ucs.br

** Mestre e Doutora em Psicologia do Desenvolvimento pela Universidade Federal do Rio Grande do Sul, UFRGS, Universidade de Caxias do Sul. E-mail: claudiabisol@terra.com.br 


\begin{abstract}
The multimedia support in learning environments can be a facilitator element for changes in the epistemological conceptions on the part of educators and apprentices. This article consists in a case study. The corpus of analysis is composed by the statements of an apprentice that interacted in the virtual learning environment of a mandatory course in a Psychology undergraduate program. Piaget's theory of Equilibration and Maturana's Biology of Knowledge are the theories that support the analysis and that give support to the construction of the cognitive and autopoietic indications. The analysis shows how the subject interacts before the exchanges made in the different scenarios of the virtual environment. The autopoietic and cognitive indications show a process of learning supported by the interaction with the other and by the interaction with the object of knowledge itself. The subject's contributions indicate a movement of authorship and construction of knowledge, assuming a participative and responsible role in the exchanges realized with the other apprentices.
\end{abstract}

Key-words: virtual learning environments; interaction; cognitive processes; autopoiesis; distance education.

\title{
Introdução
}

No pressuposto tradicional de educação, a transmissão de informações tende a preponderar sobre as trocas interativas. Os aprendizes, em geral, são colocados numa posição de receptores, enquanto que na situação de aprendizagem por construção e interação eles se encontram numa posição de interagentes. É o que Castells (1999), ao referir-se ao mundo multimídia, denomina como população receptora em contraposição a uma população interagente caracterizada pela troca interativa e pela autonomia nos processos de aprendizagem.

A nova concepção de interação e cultura cibernética está emergindo com força em diversos campos teóricos. Entretanto, faz-se necessária a formalização dessa concepção e a construção de modelos para que educadores e aprendizes realmente construam novas relações de aprendizagem em interação na cultura cibernética. A questão que se faz presente é se os ambientes virtuais (AVAs) têm contribuído para que os aprendizes construam novas relações de aprendizagem e interação na cultura cibernética. Dois aportes teóricos podem trazer contribuições para esse campo: propomos utilizar contribuições de Jean Piaget 
para o entendimento das interações e para análise dos processos cognitivos, e contribuições de Humberto Maturana para compreender a auto-organização sistêmica do sujeito que interage no ambiente virtual estudado.

O sistema humano precisa viver e experienciar para conhecer e se apropriar. O limite dessa experiência é a troca. As trocas recíprocas de ação do sujeito com o objeto de conhecimento ocorrem quando uma ação intelectual sobre o objeto retira dele qualidades que a ação e a coordenação das ações do sujeito colocam nele. Podemos analisar a troca qualitativa a partir do modelo piagetiano, considerando os fatores que regulam os processos sucessivos de equilibração no intercâmbio de pensamento e cooperação nas trocas interindividuais e intraindividuais. A partir da troca, o sujeito sai de si e volta para si, num processo contínuo de auto-regulação (PIAGET, 1973). A essa troca estamos denominando de interação. Ao discutir os mecanismos das trocas intelectuais, Piaget (1973) apresenta algumas relações possíveis nas interações com outros sujeitos: o sujeito enunciando uma proposição (verdadeira ou falsa), o seu interlocutor entrando em acordo ou desacordo, o que estabelece a possibilidade de continuação dessas interações e esse engajamento na interação confere um valor à primeira proposição que deflagrou a continuidade das trocas. Considerando as relações expressas por Piaget quanto aos mecanismos das trocas intelectuais, a expressão do ponto de vista situa-se como uma primeira relação ou proposição. O equilíbrio nas trocas ocorre quando os parceiros possuem uma escala comum de valores, conservação e reciprocidade.

$\mathrm{Na}$ abordagem piagetiana de interação encontramos também o conceito de autonomia e descentração. A autonomia, nessa teoria, não deve ser compreendida como individualismo ou centração em uma visão particular de mundo. Ao contrário, a autonomia só se opera a partir da cooperação. Piaget (1977) deixa muito claro que a autonomia se constrói a partir de relações de respeito mútuo, muito distinta da idéia de respeito unilateral a uma autoridade externa. Deve-se compreender que "[...] a autonomia é um poder que só se conquista de dentro e que só se exerce no seio da cooperação" (PIAGET, 1977, p. 321). Nesse sentido, a autonomia também não deve ser entendida como liberdade completa, mas considerando a descentração, implica em considerar o ponto de vista do outro, o que exige responsabilidade nas ações e decisões. A partir desse entendimento, fica evidente que uma nova educação e relação social só é possível quando se coloca em prática a cooperação e a reciprocidade e não apenas quando se fala de fora sobre essa realidade. A solução do conflito pode ser conseguida, transcendendo-se às diferentes centrações para chegar a uma solução "descentrada" mais avançada. No conflito sociocognitivo estão presentes a perturbação e a descentração. Dessa forma, se retoma em uma única perspectiva dois dos principais conceitos piagetianos desencadeadores do processo de equilibração. 
O fundamental, nesse processo, é a coordenação das respostas entre os sujeitos e não a simples imitação daquele que está mais avançado.

Vemos com Piaget como é construído o conhecimento em termos de significação. A inteligência constrói significações através da ação do sujeito, que transforma a realidade na qual interage e que transforma a si mesmo. O conhecer implica em um processo constante de relação entre o sujeito e o ambiente no qual o sujeito vai atribuindo significados, fazendo a sua interpretação do mundo e vai se modificando em função das resistências que o mundo lhe impõe. Esse contínuo processo de adaptação constitui a própria inteligência. Do ponto de vista piagetiano, ao tratarmos das relações sociais e conhecimento, podemos dizer que "o conhecimento humano é essencialmente coletivo e a vida social constitui um dos fatores essenciais da formação e do crescimento dos conhecimentos pré-científicos e científicos" (PIAGET, 1973). Nesse sentido, Piaget deixa claro que a interdependência do social e do cognitivo não implica em ignorar a construção individual do conhecimento. Todas as condutas supõem duas espécies de interação que são indissociáveis uma da outra: a interação entre o sujeito e o objeto e a interação entre o sujeito e os outros sujeitos. A abordagem piagetiana apresenta um aspecto dinâmico e dialético, em que a ênfase não está nem no sujeito nem no objeto, mas na interação que os une e lança em direção às novas equilibrações.

Ao preocupar-se em explicar como se dá a construção de novos conhecimentos, Piaget procura detalhar como ocorre essa construção a partir do modelo explicativo da teoria da equilibração. Falarmos em processo e construção, nessa teoria, só tem sentido a partir dos desequilíbrios. São os desequilíbrios que ativam o processo de criação e construção e mantêm a vida, através da contínua troca com o meio e da auto-regulação. Na teoria da equilibração, a fonte de progresso do desenvolvimento está nos desequilíbrios, já que esses impelem o sujeito a ultrapassar seu estado atual e a procurar avanços e novas direções. Quando esses elementos novos fazem com que as próximas assimilações sejam diferentes das anteriores, levam a equilibrações majorantes, em que o novo equilíbrio é superior ao anterior. Considerados do ponto de vista da equilibração, os desequilíbrios constituem-se fonte de desenvolvimento, pois são impulsionadores de novas equilibrações majorantes. $\mathrm{O}$ processo de equilibração pode ser compreendido como uma busca contínua de auto-regulação, ou seja, uma busca de sintonia. Esse entendimento implica numa compreensão do erro distinta da tradicional. O erro, a partir da teoria piagetiana, pode ser considerado como um observável para o sujeito. Esse é um aspecto importante na teoria, pois é fundamental o sujeito tornar o "erro" um observável para si, tendo em vista o processo no qual está envolvido e o resultado que deseja atingir. Os observáveis estão relacionados às coordenações anteriores realizadas pelo sujeito a partir de seus esquemas, ou 
seja, às suas vivências, reflexões e experiências anteriores.

Esse movimento de perturbação e busca de novas equilibrações se dá a partir da interação do sujeito com o mundo e assim vai se constituindo o conhecimento. Para Piaget, o sujeito possui graus de tomada de consciência sobre o conhecimento que ele está construindo a partir de suas interações. A tomada de consciência é desencadeada quando as regulações automáticas não são mais suficientes para dar conta do problema, sendo que é preciso procurar novos meios mediante uma regulação mais ativa, o que pressupõe escolhas deliberadas, ou seja, a consciência da ação (PIAGET, 1977).

Já as contribuições de Maturana e Varela (1997), a partir do âmbito da Biologia, vêm aprofundar o entendimento sistêmico e ampliar as discussões sobre as especificidades das interações dos sistemas vivos. Para Maturana (1997), ao falar de conhecimento devemos voltar nossa atenção para o viver. Maturana (1997) afirma que conhecer é viver, e viver é conhecer. O ser humano é definido como sistema autopoiético, compreendido como uma rede de produções de componentes na qual os componentes produzem o sistema circular que os produz. O ser e o fazer de um sistema vivo são inseparáveis, pois não existe uma separação entre produtor e produto em uma unidade autopoiética. Através do conceito de autopoiese ${ }^{1}$, os seres humanos são vistos como sistemas que produzem continuamente a si mesmos. Um sistema autopoiético é, ao mesmo tempo, produtor e produto. A autonomia, enquanto propriedade das máquinas autopoiéticas, significa que as modificações do sistema se dão à medida que procuram a conservação de sua própria organização. A noção de autonomia está ligada à noção de dependência ou interdependência e esta é inseparável da noção de auto-organização. No âmbito deste artigo, o ambiente virtual é considerado um sistema composto de microssistemas autopoiéticos. Isso significa que cada cenário é considerado um microssistema autopoiético, sendo os enunciados os elementos desse sistema. A autopoiese aqui pode ser entendida como autoprodução de relações intersubjetivas que constituem o aprender, expressas nas mensagens ou no intertextuar dos sujeitos. Essas relações compõem ou constituem os sujeitos como atores aprendentes que autoproduzem e organizam o sistema autopoiético mais amplo que é o AVA. As trocas comunicativas entre os sujeitos alimentam o próprio cenário e as trocas seguintes (textos escritos), constituindo novos rumos para a interação. Dito de outro modo, uma mensagem de um sujeito pode orientar para uma mudança de rumo nas interações ou para um novo link (um novo tema de conversação). Esse movimento de auto-organização e construção das interações opera como

1 Utilizamos o conceito de autopoiese no âmbito das Ciências Humanas conforme proposto por Maturana e Varela (1997). 
um sistema autônomo que constitui a sua própria identidade a partir das trocas que ali se realizam. No fluir das interações, Maturana (2001) considera que toda troca implica num encontro estrutural entre os interagentes, e esse encontro resulta no desencadeamento de mudanças estruturais entre os participantes do encontro. Assim, um acoplamento estrutural refere-se à dinâmica da estrutura do organismo que sempre se desenvolve acoplado ao meio. Se demando algo ao outro, estou aberto a sua proposta, a seu retorno. Segundo Maturana (2001, p. 60): "o curso de nossa mudança estrutural espontânea e reativa se faz de maneira contingente com a história de nossas interações". Ter posições diferentes não implica em negar o outro. Esse entendimento constitui-se no que Maturana (2001) denomina de objetividade-entre-parênteses.

Este artigo apresenta um estudo de caso com o objetivo de compreender o movimento autopoiético e cognitivo de um sujeito que interagiu no ambiente de aprendizagem "Teorias da Aprendizagem". Em estudos de caso, fontes de evidência múltiplas e situadas em um conjunto contemporâneo de acontecimentos são utilizadas para construir a análise (YIN, 2001). Utilizamos, para a análise do processo de aprendizagem do sujeito aprendente, suas interações nos diferentes cenários do ambiente virtual de aprendizagem, definindo indicadores autopoiéticos e cognitivos a partir das abordagens teóricas elencadas.

\section{$O$ contexto da pesquisa}

A coleta de dados para essa pesquisa foi realizada em um AVA concebido para a disciplina obrigatória "Teorias da Aprendizagem", ministrada no terceiro semestre de um curso de graduação em Psicologia. No ato da matrícula, os alunos tiveram a opção de escolha de realizar a disciplina na modalidade presencial ou semipresencial. Era a segunda versão da modalidade semipresencial para essa disciplina. Os primeiros encontros aconteceram presencialmente em laboratório, momento em que os alunos foram orientados tanto nos aspectos gerais de conteúdo da disciplina quanto no uso e apropriação do ambiente e nas suas ferramentas de interação. No total dos 19 encontros do semestre, 6 aconteceram presencialmente e o restante em atividades a distância usando o AVA. Os encontros presencias eram voltados para orientações, síntese de unidades de estudo e avaliação. Os primeiros encontros presenciais foram fundamentais para a construção de um vínculo entre os atores desse processo (alunos e professora), além de dar segurança e autonomia no uso do ambiente virtual.

O ambiente foi construído em HTML utilizando vários editores de páginas 
Web, formulários em CGI e linguagens Perl, JavaScript, C e C++. Foi concebido apoiando-se na metáfora de navegação e constituindo-se como um mapa náutico. Foram criados diferentes contextos de interação, denominados de cenários: Ilha do Sossego, Biblioteca de Alexandria, Orientação aos Navegantes e Plano de Viagem, este último contendo Fórum, Chat, Estudos de Caso e Diário de Bordo. A Ilha do Sossego constituiu-se no espaço para trocas informais, suportadas através de um formulário ou mural. A Biblioteca de Alexandria, representada pelo farol, agrupou textos da disciplina, links e textos dos alunos, organizados na forma de hipertextos. A Orientação aos Navegantes, representada pela rosa dos ventos, apresentava o projeto de ensino e a proposta da disciplina. O pergaminho representou o Plano de Viagem e nele encontra-se a idéia de trocas cooperativas, registro, sistematização do conhecimento, escrita. Nesse cenário ocorreram a maior parte das construções e interações através de formulários, fórum de discussão, e-mail, chat e lista de discussão. Tanto as interações síncronas quanto as assíncronas ficaram registradas no ambiente. A proposta tinha a problematização e a interação como princípios para a aprendizagem. As estratégias de ensino-aprendizagem foram organizadas a partir de estudos de casos, discussão de textos e resolução de problemas.

\section{Análise da interação: movimento autopoiético e cognitivo}

O corpus de análise deste estudo é composto pelos enunciados de um aprendiz que interagiu no AVA. Para a análise foram destacadas as particularidades de um sujeito, evitando generalizações e buscando estabelecer uma relação de complementaridade na compreensão das interações no ambiente e do processo de aprendizagem. A partir das interações, para este artigo, foram eleitos indicadores do movimento cognitivo: expressão do ponto de vista, descentração, desequilibração e tomada de consciência. Como indicadores do movimento autopoiético elegemos: concepção de organização, demanda ao outro, confrontação de perspectiva e auto-organização de si e do grupo.

A análise do processo de interação do sujeito D1 mapeou as interações que ocorreram, durante os quatro meses da disciplina, nos diferentes cenários do ambiente virtual (Ilha do Sossego, Fórum e Diário de Bordo), num total de 51 postagens (análise de textos, respostas a colegas, críticas, textos e reflexões pessoais). Como o conteúdo dessa disciplina discute as diferentes teorias da aprendizagem, as postagens e contribuições tratam dessas concepções e teorias.

Nessa análise buscou-se identificar como as interações aconteceram no 
sentido autopoiético e cognitivo e que condutas são evidenciadas nas trocas interindividuais. Nessa perspectiva, analisam-se suas interações nos cenários interindividuais (fórum e Ilha do Sossego) e as reflexões do sujeito postadas no cenário Diário de Bordo, o único espaço intraindividual.

As interações de D1 foram analisadas considerando as suas características mais marcantes, ou seja, como este influenciou e foi influenciado pelos interlocutores. Assim as mensagens foram mapeadas considerando o seu direcionamento a todos, a um sujeito específico, como retorno para todos com resgate de alguma idéia ou argumentação ou retorno para um sujeito específico.

O sujeito D1 realizou poucas interações no cenário Ilha (cinco no total), sendo todas destinadas a todos os interagentes ou aprendizes. Embora as interações de D1 no cenário Ilha tenham sido poucas, suas interações nos demais cenários foram intensas e produtivas. O cenário Ilha, para D1, parece não ter sido tão fundamental para suas interações quanto foram os demais cenários. No entanto, foi o cenário que pôde evidenciar mais explicitamente para a maioria dos estudantes o vínculo estabelecido.

No fórum, D1 faz uma série de contribuições, sendo que a maioria é identificada como uma mensagem direcionada a todo o grupo. Somente em duas mensagens, D1 resgata alguma idéia para continuar o debate. No sentido geral, temos a maioria das mensagens constituídas como expressão do ponto de vista. Esse indicador deixa transparecer um movimento de autoria do sujeito, pois, como veremos mais adiante, D1 se coloca como responsável pelo seu texto, assume sua posição e atua na construção da rede de sentidos construída pelo grupo. No entanto, a expressão do ponto de vista também pode ser compreendida como uma construção do sujeito com ele mesmo e com os textos sem, necessariamente, reconstruir suas concepções a partir da interação com o outro.

Mas se faz necessário penetrarmos no conteúdo das mensagens, para podermos compreender melhor o processo vivenciado por D1. Suas primeiras mensagens refletem sua concepção de aprendizagem, seu interesse por determinados temas e sua concepção de organização, como vemos nos extratos a seguir:

Ufa! Foi-me um alívio ler "provisórias" após a palavra "certezas", pois penso que redigir "certezas perpétuas" é o mesmo que medir a profundidade de um rio valendo-se dos dois pés... [...] No caso da aprendizagem em sala de aula, o mais importante não é ensinar, mas criar condições nas quais os alunos possam aprender. Isto, aliás, já dizia e fazia Einstein. (A1 - F D1 - 13/03) 
[...] Pode-se dizer, então, que a liberdade criadora é uma das melhores formas de aprendizagem ou uma das mais eficientes? Oscar Wilde, um dramaturgo irlandês do século passado, disse certa vez que "nada daquilo que realmente vale a pena saber pode ser ensinado", no caso, por outrem a nós. Até que ponto pode-se dizer que esta afirmação é veraz? A aprendizagem não é algo uniformizado? Pode-se também defini-la como "uma modificação relativamente duradoura do comportamento". Mas quando ela se faz mais duradoura? Ou valendo-se de que ela se faz mais permanente? (A1 - F - D1 - 13/03)

Nesses parágrafos já é possível identificar algumas de suas concepções e contradições com relação às teorias da aprendizagem, que nos possibilitam pensar sobre o seu processo cognitivo. Vemos que, ao mesmo tempo em que afirma que mais do que ensinar é importante criar condições para aprender, também afirma que a aprendizagem seria algo uniformizado e uma modificação relativamente duradoura do comportamento. Na teoria da equilibração, a fonte de progresso do desenvolvimento está nos desequilíbrios, já que esses impelem o sujeito a ultrapassar o seu estado atual e a procurar avanços e novas direções. Por esses enunciados de D1, podemos identificar um estado de desequilibração, ou seja, um movimento de perturbação. Talvez, nesse momento, ele ainda não tenha se dado conta das contradições expressas em seu texto.

No entanto, resgatando sua contribuição no cenário Diário de Bordo, alguns dias depois, D1 expressa um movimento de tomada de consciência, no qual já se dá conta de algumas contradições e faz um movimento de reconstrução. Vejamos, a seguir, o extrato de seu Diário:

Há pouco nosso barco deixou o cais e, sequer avistamos o alto-mar, já estou questionando-me acerca das idéias, [...] Para facilitar o entendimento, vou contar-lhe uma breve história: Há cerca de um ano foi-me solicitada a redação de um artigo acadêmico sobre um assunto pelo qual fosse apaixonada e cuja tese realmente acreditasse, a qual deveria defender. $\mathrm{O}$ assunto por mim escolhido foi o "papel do professor" e o objetivo era "provar que o mesmo é o protagonista da escola, o fator decisivo para a qualidade da educação e também o maior agente potencializador de talentos, em sala de aula". É recente a nossa partida para esta viagem, mas a introspecção a que ela já me conduz faz-me sentir envergonhada e triste. O professor desempenha um importante papel na escola, sim; todavia, é coadjuvante da história que se escreve todos os dias em sala de aula. [...]E é esse fato que contraponho agora à frase que li esta semana em um artigo acerca da epistemologia genética de Piaget, na qual o professor Yves de La Taille, do Instituto de Psicologia da USP, diz que "a teoria de Piaget 
salvou o homem". Ouso censurá-lo, afirmando que o homem ainda não percebeu o quanto a teoria de Piaget pode ajudá-lo a salvar as gerações futuras, bem como a si mesmo. [...]. Quando o educador der os primeiros passos em direção a esta humildade, desprovido até mesmo das lembranças de sua onipotência, talvez neste instante ele beire ao papel de protagonista; ao lado do aluno, quem sabe ele se faça também um lutador disposto a crescer e aprender um pouco mais. De nosso barco, neste momento, já é possível avistar o alto-mar e sinto-me tão mais leve e menos culpada por ter percebido tão cedo a minha erronia de outrora e ter o ensejo de com ela "aprender". (A1 - D - D1 - 20/03)

A tomada de consciência já começa a aparecer, fruto de vivências e reflexões sobre o viver e o fazer cotidiano, pois, além de estudante, D1 também é professor. Segundo Piaget (1977), a tomada de consciência é desencadeada quando as regulações automáticas não são mais suficientes. Assim, é preciso buscar novos meios através de uma regulação mais ativa e mediante escolhas que pressupõem a consciência.

Nesse extrato do Diário de Bordo, destacamos ainda a autoria aparecendo como um elemento significativo, pois D1 utiliza a idéia de um autor para construir uma argumentação própria, marcando uma posição. $\mathrm{O}$ movimento de reconstrução de si, a partir da intervenção do outro, também aparece aqui a partir da interação com o texto, ou seja, o leitor vai construindo a sua autoria fazendo recortes e penetrando no texto ou na teoria.

Voltando às contribuições, identificamos alguns extratos em que D1 expressa seu ponto de vista, colocando-se num lugar de autoria:

Ao longo da leitura, foi-me possível identificar e enquadrar os vários professores que tive e tenho nos três modelos apresentados (o que indica compreensão e aprendizagem) e acredito serem evidentes as seqüelas que os dois primeiros modelos deixaram em ambos professor e aluno: culpa e fracasso. (A1 - F - D1 - 09/04)

Não sei se a tendência é o abandono da postura diretiva e passagem para a não-diretiva. Porém, se é de fato isto que ocorre, penso ser porque aos olhos docentes, renunciar à intervenção no processo de aprendizagem do aluno é mais cômodo ou mais prático que empenhar-se em aprender 
o quanto este aluno já construiu; renunciar a esta função fundamental é também, penso eu, menos agressivo que afirmar "somente eu tenho algo a ensinar". (A1 - F - D1 - 16/04)

Poder colocar-se no lugar de autor, assumir a responsabilidade pela sua posição e sua idéia é possível quando as relações se fundamentam no respeito mútuo. Os processos intelectuais, portanto, não podem ser dissociados da educação moral, como destaca Piaget (1998, p. 165):

Não conseguiríamos promover a plena liberdade de consciência frente aos problemas políticos (quer se trate de questões de classes sociais, de nacionalismo, de conflitos ideológicos, etc.) em indivíduos formados para cooperação moral, mas que, por outro lado, estejam submetidos a verdades intelectuais prontas.

Autorizar-se a questionar as idéias do professor, dos colegas e dos teóricos é um movimento gradativo, portanto, que se inicia na tomada de consciência a respeito de possíveis incongruências, de divergências entre posições teóricas ou entre a teoria e o que é experienciado na prática, e da existência de pontos de vista discordantes. No Diário de Bordo, D1 expressa sua compreensão das interações no ambiente virtual, refletindo o seu movimento de tomada de consciência.

O contato com a marinheira-professora tem sido pequeno, se comparado às trocas efetuadas com os demais marinheiros... e a aprendizagem faz-se também - senão mais - possível desta forma. [...] Entristeceu-me perceber quão falha foi a minha formação para o exercício do magistério, onde foime imposta a desconhecida prática construtivista sem a chance prévia de desvelar por inteiro esta e outras práticas pedagógicas... Não me recordo também de ter ouvido alguém indagar-me sobre "que professor desejava ser e que cidadãos almejava conduzir meus alunos a serem", indagação esta, a meu ver, essencial para o exercício consciente e efetivo da ação docente. (A1 - D - D1 - 29/03)

A tomada de consciência aconteceu à medida que a vivência no ambiente $\mathrm{e}$ as reflexões foram tornando-se significativas e avançando ao longo da disciplina. Essa constatação vem ao encontro do que Piaget (1977, p. 198) afirma sobre esse 
processo, ou seja, "a tomada de consciência parte da periferia (objetivos e resultados) para as regiões centrais da ação, quando procura alcançar o mecanismo interno dessa (reconhecimento dos meios empregados, motivos de sua escolha ou de sua modificação durante a experiência, etc.)". A seguir, destacamos mais alguns extratos que contribuem na compreensão do processo de D1:

Constrói-se tão pouco e tão lentamente quando se está só. A interação, ouso afirmar, assemelha-se de certa forma ao ato de amar, onde a troca transcende a entrega e onde o doar-se de um é comumente enriquecido pela doação do outro. O processo de interação traça seus passos paralelo ao de aprendizagem. Quanto mais avança o primeiro, mais espaçados são os passos do segundo. À medida que traspassamos o horizonte deste mar, sinto-me traspassada pelas trocas que efetuo e, nesse fundir de conhecimentos, sinto-me tão maior do que outrora fui. $\mathrm{O}$ processo de interação é um processo de vitória mútua e todo aquele que por ele optar deve, antecipadamente, abrir mão do que sabe para, de braços abertos, receber - multiplicando - o conhecimento que está por vir.

Quanto mais interagimos, mais adentramos o mar do conhecimento e mais nos adentra a aprendizagem. (A1 - D - D1 - 18/04)

Ao expressar estar "traspassada pelas trocas que efetuo", D1 evidencia, novamente, o encontro estrutural e o desencadeamento de mudanças a partir dessa troca, ou seja, segundo Maturana (1997), o acoplamento estrutural que, pela sua própria dinâmica, desenvolve-se no curso das interações.

Voltando às discussões no Fórum, vemos que, embora tenhamos somente duas contribuições em que D1 resgata alguma idéia apresentada por um interlocutor, nelas fica evidente que a possibilidade de considerar as contribuições dos colegas permite a D1 aprimorar a sua posição, num movimento de construção conjunta de saberes:

Quando D2 coloca que é mais importante saber como ocorre o processo de aprendizagem dos alunos do que qualquer outro conteúdo a lhes ensinar, pensei no quanto a essência da aprendizagem se perde pelo caminho que o professor percorre por desconhecer tão simplesmente "o que é essencial, fundamental" para a construção do conhecimento... impedindo, simplesmente, que os alunos avancem "inúmeros degraus" acima dos que se postam os conhecimentos que instruíram em outros tempos e sempre. (A1-F-D1-16/04) 
Ao considerar a posição do outro, é possível que novos rumos surjam e, assim, efetive-se a construção de novos possíveis. Nas interações do Fórum encontramos mais contribuições que resgatam a idéia de um parceiro do que a simples expressão do ponto de vista. Encontramos, assim, a presença dos indicadores que evidenciam mais o envolvimento com o outro, como a confrontação de perspectivas, a descentração, e a auto-organização. É importante salientar que nessa perspectiva pode haver oposição à idéia e à posição apresentada pelo outro, mas essa oposição ou negação traz consigo o entendimento de que o não partilhar da idéia do outro não significa que essa idéia esteja equivocada em sentido absoluto. A oposição à posição do outro se faz num sentido responsável, apoiada na percepção da realidade "multidimensional" pelo sujeito. Os enunciados do indicador auto-organização evidenciam o movimento autopoiético, de auto-organização e de construção do grupo, concebido como sistema cognitivo. Embora o movimento de auto-organização esteja contemplado em todo o processo de interação, esses enunciados evidenciam a proposta de continuidade ou reorientação das próximas interações, ou seja, a busca de novos caminhos para a própria organização e para a organização do ambiente.

Observa-se no relato a seguir que D1 menciona explicitamente B e S2 para ressaltar sua concordância, e depois faz um chamamento coletivo ("Colegas"), agregando o grupo em torno de uma tarefa que ela toma a iniciativa de organizar. São três atitudes em relação à aprendizagem: tenta organizar as idéias afins (auto-organização de si ou do grupo), compartilha o resultado de seu trabalho com os outros (expressão de seu ponto de vista) e convida-os ao diálogo (demanda ao outro). Essas três atitudes e seus respectivos indicadores autopoiéticos e cognitivos marcam uma postura ativa e não passiva em relação ao objeto de conhecimento e em relação aos demais sujeitos que compartilham o ambiente de aprendizagem:

Concordo com a B e a S2 quando dizem (ou teclam) que é necessário oportunizar a todos os alunos o contato com a informática e acrescento que, antes da chegada da máquina às escolas, é preciso que se formem professores não como instrutores, mas como construtores, junto aos alunos, de novas aprendizagens. [...] Quando minha xará diz que será considerado analfabeto todo sujeito que não souber manusear um computador, arrepiome só de pensar em tal realidade. Em termos de nação brasileira, é evidente que a massa desprivilegiada é bem maior que o número de pessoas que pode e poderá ter contato com a máquina. Sugiro que pensemos a respeito e também em alternativas de solução para que a maioria da população não seja "duplamente analfabeta"... antes que seja tarde demais. (A1 - F (grupo interdisciplinar) - D1 - 26/05) 
COLEGAS...Como demonstramos ter idéias afins, tentei juntar todas elas em uma conclusiva intervenção. Leiam-na e proponham mudanças, para que logo mais eu envie-na às demais colegas pelo chat. (A1 - F D1 - 20/06)

A postura participativa de D1 aparece nessa atividade pedagógica de Estudo de Caso, proposta para ser realizada em subgrupos entre os alunos da turma. Cada grupo sugeria uma intervenção a ser apresentada ao grande grupo em um chat, para posteriormente buscar-se avaliar e incrementar as possibilidades de intervenção. Nessas interações, como foi identificado acima, D1 assume um papel participativo, retomando idéias apresentadas e encaminhando propostas de organização do grupo e reorganização das propostas apresentadas pelos parceiros.

Já no Diário de Bordo, D1 expressa sua percepção a respeito das interações no ambiente virtual e a tomada de consciência dessas trocas como propulsoras do processo cognitivo de cada sujeito. Expressa também a sua concepção de organização.

A interação no ambiente virtual, contudo, ficou um tanto prejudicada, em virtude de enviarmos nossas contribuições sem a preocupação em ler as das colegas e posicionar-se quanto às mesmas. E, nesse sentido, percebo quão fundamental foi a interferência da professora que despertou-nos para este e tantos outros pontos de extrema relevância para a experiência.

A interação ocorreu à medida que influenciamos nos processos alheios e foi influenciado o nosso pelas colegas, enfim, à medida que interferimos e contribuímos umas para as construções das outras.

A integração despontou no momento em que nos sentimos responsáveis umas pelas outras e isto me pareceu evidente do princípio ao fim da experiência.

A cooperação, por sua vez, foi conseqüência da interação e integração que descrevi acima e despontou por existirem interesses e linguagem afins entre nós todas e o desejo de operar sobre o processo cognitivo alheio. (A1 - D - D1 (07/07) 
No seu último Diário de Bordo, D1 retoma e avalia o processo vivenciado:

Esta experiência afetou-me a eternidade, adianto-me em dizer.[...] A dificuldade relativa à adaptação e manuseio do ambiente virtual era evidente no início, mas foi logo superada, graças à cooperação da professora e das colegas de barco. [...] Ao perceber quão importante era receber a opinião das colegas sobre as minhas produções, inverti a luva, passando a discorrer sobre as produções alheias, numa exitosa tentativa de interação.

Quanto às produções no diário de bordo, a cada nova elaboração (que me custava horas), as anteriores me pareciam pequenas e fracas. Isso porque a cada um eu mostrava-me maior em relação ao construído e mais exigente em relação à futura produção.[...]

E por falar em produção, quando nos foi questionado se sempre, antes de iniciarmos a experiência, produzíamos tanto e tão bem, foi que me dei conta do tanto tempo que eu não escrevia com prazer sobre coisas que provinham do âmago de mim mesma e com sinceridade não sei se voltarei a fazê-lo, visto as oportunidades para isso serem tão limitadas.[...]

$\mathrm{O}$ aprendido a mim pareceu fluir sempre mais à medida que mais nos questionávamos e produzíamos sobre nossas próprias indagações acerca das leituras efetuadas. Foi, pois, exatamente esta a minha forma de estudo: indagando-me acerca de tudo que me era posto em contato relativo aos temas propostos. (A1-D-D1-07/07)

Ao tomar sua vivência na disciplina e no ambiente virtual como objeto de reflexão, D1 fez incidir sobre ela uma operação que a lançou a um outro patamar, no qual pôde estabelecer novas relações e operações sobre a mesma. Isso exigiu uma reconstrução da própria vivência, agora separada da sua realidade empírica, constituindo-se no processo de abstração reflexionante. 


\section{Considerações finais}

Considerando as interações de D1 no AVA, é possível dizer que a presença das categorias autopoiéticas e cognitivas nos seus enunciados evidencia um processo de aprendizagem sustentado pela interação com o outro e pela interação com o próprio objeto de conhecimento. Suas contribuições comprovaram um movimento de autoria e de construção de conhecimento, assumindo um papel participativo e responsável nas trocas efetuadas com os demais aprendizes.

As condutas cognitivas e autopoiéticas de D1 foram destacadas ao longo da análise, evidenciando a complexidade do processo de aprendizagem. No processo de D1 foi identificado o movimento de tomada de consciência tanto nos Diários de Bordo, como em suas reflexões no Cenário Fórum. Pelas produções nos Diário de Bordo fica evidente que o processo de meta-reflexão é o mecanismo cognitivo fundamental na construção de condutas autônomas e cooperativas. Isso confirma a afirmação de Ramos (1996, p. 223), de que "a meta-reflexão permite a transcendência libertadora que configura a autonomia. Só consciências livres são capazes de se auto-refletir". Acreditamos que essa riqueza pôde ser evidenciada em virtude de dois fatores principais: porque contamos com um ambiente virtual em que as reflexões e contribuições podiam ser registradas e retomadas e porque a metodologia de interação baseava-se numa relação de respeito mútuo. Além disso, é importante considerar que o próprio conteúdo da disciplina eram as teorias da aprendizagem, gerando um duplo movimento reflexivo sobre o aprender a partir dos conceitos a serem aprendidos e do seu processo de aprendizagem.

Traçar o percurso de um aprendiz no ambiente virtual de aprendizagem tem o sentido de evidenciar algumas particularidades de seu processo, principalmente com relação às interações e ao seu pensar e agir no uso do ambiente virtual. Se fôssemos analisar individualmente todos os aprendizes, possivelmente encontraríamos particularidades no movimento cognitivo e autopoiético, ou seja, o não aparecimento de alguns indicadores e o surgimento de outros. Da mesma forma podem aparecer variações na forma como cada aprendiz é capaz de apropriar-se ou não das estratégias que permitem a cooperação, a tomada de consciência e a autoria. Outro aspecto possível de ser analisado é o movimento cognitivo e autopoiético da comunidade de aprendizagem (VALENTINI, 2006). Pelos demais relatos e análises dos processos de outros aprendizes, temos indicadores de que as vivências, ao longo do semestre, aliadas às estratégias do professor, contribuíram para a apropriação e a ressignificação do ambiente e para a construção de novas possibilidades em relação às interações e à construção do conhecimento em ambiente virtual. 


\section{REFERÊNCIAS}

CASTELLS, M. A sociedade em rede (A era da informação: economia, sociedade e cultura), v. 1. São Paulo: Paz e Terra, 1999.

MATURANA, H. A ontologia da realidade. Belo Horizonte: Ed. UFMG, 1997.

MATURANA, H. Emoções e linguagem na educação e na política. Belo Horizonte: Editora UFMG, 2001.

MATURANA, H.; VARELA, F. De máquinas e seres vivos: autopoiese - a organização do vivo. 3. ed. Porto Alegre: Artes Médicas, 1997.

PIAGET, J. Biologia e conhecimento. Petrópolis: Vozes, 1973.

PIAGET, J. A tomada de consciência. São Paulo: Melhoramentos, 1977.

PIAGET, J. Sobre pedagogia. São Paulo: Casa do Psicólogo, 1998.

RAMOS, E. M. Análise ergonômica do sistema hiperNet buscando o aprendizado da cooperação e da autonomia. Tese (Doutorado em Engenharia Produção e Sistemas) - Programa de Pós Graduação em Engenharia Produção e Sistemas, Universidade Federal de Santa Catarina, Florianópolis, 1996.

VALENTINI, C. B. Interação em ambiente virtual de aprendizagem: redes sociocognitivas e autopoiéticas. Colabora: Revista digital da CVA-Ricesu, v. 3, n. 11, 2006.

YIN, R. Estudo de caso: planejamento e métodos. Porto Alegre: Bookman, 2001.

Texto recebido em 19 de abril de 2007. Texto aprovado em 13 de fevereiro de 2008. 